\title{
Micropropagación in vitro de Nothofagus alpina utilizando fitohormonas
}

\section{In vitro micro propagation of Nothofagus alpina through the use of phytohormones}

\author{
${ }^{\bullet}$ Luz García Cruzatty ${ }^{1,2,3}$, Judith Carrasco ${ }^{1}$, Jaime Morante Carriel$^{2}$, Ricardo Luna Murillo ${ }^{4}$,
} Betty González Osorio ${ }^{2}$, Jessenia Castro Olaya ${ }^{1}$

${ }^{1}$ Facultad de Ciencias Forestales y Recursos Naturales, Universidad Austral de Chile, Isla Teja, Valdivia, Chile. UACh, Campus Isla Teja, Casilla 567.•lgarcia@uteq.edu.ec; jcarrasco@uach.cl; jesseniacastro@hotmail.com

${ }^{2}$ Facultad de Ciencias Ambientales, Universidad Técnica Estatal de Quevedo. Campus Ing. Manuel Haz Álvarez, km 1.5 vía a Santo Domingo de los Tsáchilas. EC.120501.Quevedo,Ecuador.bgonzalez@uteq.edu.ec ${ }^{3}$ Facultad de Ingeniería Agronómica, Universidad Técnica de Manabí. Campus Experimental "La Teodomira", km 13 1⁄2 vía Santa Ana. Santa Ana, Manabi, Ecuador.

${ }^{4}$ Departamento de Investigación Cientifica. Universidad Técnica de Cotopaxi, Av. Los Almendros y calle Pujili, Sector La Virgen. Cotopaxi.La Maná.patoricardo@yahoo.es

\section{Resumen}

$N$ Tothofagus alpina es una de las especies forestales más importantes del Sur de Chile y Argentina, países donde se ha empezado con programas de mejoramiento genético. La micropropagación es una técnica muy útil en la clonación de árboles con fines de mejoramiento, por tanto, los objetivos planteados en esta investigación fueron: determinar la mejor concentración de fitohormonas 6-bencilaminopurina (BAP) y ácido indol butírico (AIB) y, el medio de cultivo idóneo para inducir el enraizamiento de brotes y la brotación de secciones nodales de $N$. alpina. Se evaluaron los medios de Murashige Skoog (MS) y Wood Plant Medium (WPM), con la mitad de los macronutrientes (enraizamiento) y los micronutrientes completos (multiplicación), suplementado con peptone $(0.10 \%)$, sacarosa $(2.00 \%)$, agar $(0.70 \%)$ y diferentes concentraciones de auxinas. El medio MS suplementado con $2 \mathrm{mg} \mathrm{L}^{-1}$ de AIB resultó mejor para inducir la producción de las raíces, tanto en número como en la longitud de la raíz principal. El mayor porcentaje de enraizamiento se registró en el medio WPM suplementado con $2 \mathrm{mg} \mathrm{L}^{-1}$ AIB. Los tratamientos para inducir multiplicación que incluyeron citoquinina originaron callos y no enraizaron; siendo mayor la presencia de callos en el medio WPM. Se sugiere que la aplicación de citoquininas no es indispensable para la brotación, puesto que en los tratamientos testigos hubo una buena brotación; lo que hace suponer que el material vegetal utilizado tiene suficiente niveles endógenos de esta fitohormona.

Palabras clave: cultivo in vitro, organogénesis, Nothofagus alpina, medios de cultivo, enraizamiento.

Recibido: 30-octubre-2014. Recibido en forma corregida: 30-diciembre-2014 Aceptado: 25-marzo-2015.

Publicado como ARTÍCULO CIENTÍFICO en Ciencia y Tecnología 8(1): 1-10 Junio de 2015

\begin{abstract}
Wothofagus alpina is one of the most important 1 forest species in the south of Chile and Argentina, where genetic improvement programs have been started. Micropropagation is a very useful technique when cloning trees for improvement purposes, so the objectives stated in this investigation were: to determine the best of 6-bencilaminopurine phytohormones (BAP) and the ideal culture medium to induce bud rooting and $N$. alpina nodal section sprouting. Murashige Skoog (MS) and Wood Plant (WPM) media were evaluated with half macronutrients (rooting) and full micronutrients (multiplication), supplemented with $0.10 \%$ peptone, $2.00 \%$ saccharose, $0.70 \%$ agar and different auxin concentrations. MS medium supplemented with $2 \mathrm{mg} \mathrm{L}^{-1} \mathrm{AIB}$ was found to be the best for inducing root formation in both number and length of the main root. The greatest percentage of rooting was shown by WPM supplemented with $2 \mathrm{mg} \mathrm{L}^{-1}$ AIB. Treatments with cytokinin for inducing multiplication originated calluses and failed to root, with a prevalence of calluses in WPM medium. The application of cytokinin is not indispensable for sprouting since in witness treatments, a greater number of buds was observed. This leads to the idea that the plant material used contains enough endogenous levels of this phytohormone
\end{abstract}

Key words: in vitro culture, organogenesis, culture media, rooting, Nothofagus alpina. 


\section{Introducción}

$\mathrm{L}$ as plantaciones forestales tienen una importante función ambiental, al proveer materia prima a la industria forestal y al reducir la presión sobre los bosques naturales. En este aspecto, es importante el aporte de las innovaciones en genética y biotecnología para obtener árboles de buen crecimiento y con características deseadas (Sedjo, 1997). Las técnicas de propagación clonal de individuos sobresalientes han mostrado ser herramientas efectivas para aumentar la productividad forestal.

Especies del género Nothofagus están distribuidas en el Sur Occidente de la cordillera de Los Andes en Chile y Argentina, de las cuales Nothofagus alpina Oerst es considerada la más importante junto a $N$. obliqua; principalmente por la calidad de su madera y relativa abundancia en estos países. Sus bosques han sido disminuidos notablemente, aprovechando los mejores individuos, por lo que después de 1980 quedaron muy pocos árboles con buena calidad fenotípica (Schlatter y Steuer, 2005). Por esta situación; en los últimos años, se han realizado muchos esfuerzos para la conservación, mejoramiento genético y desarrollo de tecnologías para la propagación vegetativa de esta especie. En este sentido, la Corporación Nacional Forestal de Chile (CONAF) y la Cooperativa de Mejoramiento Genético Forestal (CMGF) emprendieron un programa de conservación y mejoramiento de $N$. alpina, realizando el establecimiento, en el año 1989, del huerto semillero clonal "Huillilemu" para la producción de semilla mejorada (García, 2014).

En la actualidad existe una fuerte demanda, con fines de reforestación, por material vegetal de esta especie; y en este huerto semillero, aunque ha tenido periodos con muy buena floración, el mayor porcentaje de las semillas producidas han resultado vacías (García, 2014). Para aumentar la productividad del recurso y obtener un beneficio sostenible, se ha puesto énfasis en la aplicación de herramientas biotecnológicas y silvícolas en la propagación de esta especie (Sabja et al., 2008). Entre las estrategias de mejoramiento de especies forestales se consideran técnicas de propagación asexual (macropropagación y la micropropagación) que permiten transferir toda la varianza genética a los descendientes, duplicando la ganancia genética asociada a los esquemas sexuales de propagación (Ikemori et al., 1994).

En este sentido, Sabja et al. (2008) desarrolló un protocolo para la clonación de individuos superiores de $N$. alpina, logrando establecer in vitro el $37 \%$ de los genotipos seleccionados en el programa de mejoramiento genético antes mencionado. Sin embargo, las vitroplantas obtenidas han pasado por varios subcultivos a través del tiempo, disminuyendo la capacidad de propagación mediante esta técnica. Según Muhitch y Fletcher (1985), las células, al envejecer en cultivo, sintetizan y acumulan productos nocivos para el crecimiento vegetal, disminuyendo la tasa de proliferación a medida que el número de subcultivos aumenta.

Con estos antecedentes se orientó un ensayo para determinar las condiciones óptimas para micropropagar los árboles plus de $N$. alpina (seleccionados por la Cooperativa de Mejoramiento Genético de Chile), a partir de las vitroplantas previamente establecidas. El objetivo general fue realizar micropropagación in vitro de $N$. alpina utilizando las fitohormonas 6-bencilaminopurina (BAP) y ácido indol butírico (AIB), fase de multiplicación y enraizamiento. Específicamente, se planteó determinar la mejor concentración de hormonas para inducir el enraizamiento de brotes y la brotación de secciones nodales; conocimientos que serán de utilidad para continuar con la multiplicación clonal de los individuos seleccionados.

\section{Materiales y métodos}

\section{Material vegetal inicial}

Se utilizaron vitroplantas obtenidas a partir de los clones RA120, RA26, RA19, RA23, RA60, RA18, RA11, establecidas por la Cooperativa de Mejoramiento Genético de Chile en asociación con la Universidad Austral de Chile; cultivadas bajo condiciones asépticas, obtenidas a partir de árboles plus de $N$. alpina que tenían entre 40 y 60 años de edad al momento de obtener los explantes. Estos árboles, ubicados a lo largo del área de distribución natural de la especie $\left(35^{\circ}\right.$ a $\left.41^{\circ} \mathrm{S}\right)$, fueron seleccionados fenotípicamente con base en la rectitud y volumen, con una intensidad de selección promedio de un árbol cada 50 hectáreas. El material vegetal utilizado para la obtención de las vitroplantas iniciales, corresponde a brotes apicales de yemas en desarrollo. Las plantas obtenidas fueron sometidas a subcultivos sucesivos durante cinco años. Los datos acerca de los medios de cultivo y condiciones de temperatura y luminosidad utilizados inicialmente para el establecimiento de estas vitroplantas y posteriores subcultivos, no se han publicado.

\section{Desarrollo del experimento}

Para el ensayo de inducción de la brotación, las plántulas de inicio fueron segmentadas en estaquillas con 2 a 3 nudos, y fueron colocadas de 
forma horizontal sobre el medio de cultivo. Para el ensayo de enraizamiento se utilizaron brotes apicales de aproximadamente 3 a $4 \mathrm{~cm}$ de largo. Se marcó cada tubo con el código de la especie, y la fecha de siembra. Los explantes fueron trasladados a la cámara de incubación con temperatura de 22 a $24^{\circ} \mathrm{C}$, una intensidad lumínica de aproximadamente 3000 Lux y un fotoperiodo de 16 horas. Los ensayos fueron evaluados a los 40 días después del establecimiento.

\section{Tratamientos}

En el ensayo de enraizamiento se probó dos medios de cultivo: MS (Murashige y Skoog, 1962) y Wood Plant Medium (WPM) (Lloyd y Mccown, 1981) con la mitad de los macronutrientes, suplementado con peptone $(0.10 \%)$, sacarosa $(2.00 \%)$, agar $(0.70 \%)$. El pH se ajustó a 5.80. Se utilizaron diferentes concentraciones de auxinas $\left(0.50 ; 1\right.$ y $2 \mathrm{mg} \mathrm{L}^{-1}$ de AIB sola y combinada con $0.50 \mathrm{mg} \mathrm{L}^{-1}$ de BAP, más un testigo. A los 35 días se evaluó el número y longitud de la raíz mayor $(\mathrm{cm})$, porcentaje de enraizamiento, sobrevivencia y callosidad.

En el ensayo de multiplicación de brotes se probó los medios MS y WPM (Lloyd y Mccown, 1981), con los macronutrientes completos, suplementados con peptone $(0.10 \%)$, sacarosa $(3.00 \%)$, agar $(0.70 \%)$. El $\mathrm{pH}$ fue regulado a 5.80. Se adicionó auxinas AIB $(2 \mathrm{mg}$ $\mathrm{L}^{-1}$ ) combinada con $0,0.50,1$ y $2 \mathrm{mg} \mathrm{L}^{-1}$ de citoquinina BAP más un testigo. La evaluación del ensayo fue a los 40 días. Las variables evaluadas número y longitud de brotes, número de hojas, porcentaje de brotación y callosidad.

\section{Diseño experimental}

Para evaluar el efecto de las fitohormonas y medios de cultivo sobre la productividad de los brotes de $N$. alpina se establecieron dos experimentos. El primero orientado a evaluar el efecto de tres niveles de AIB $\left(0.50,1\right.$ y $\left.2 \mathrm{mg} \mathrm{L}^{-1}\right)$, dos de BAP $(0$ y 0.50 $\mathrm{mg} \mathrm{L}^{-1}$ ) y dos medios de cultivo (MS y WPM) sobre la inducción de raíces en los explantes de N. alpina; para tal efecto los factores fueron ordenados de forma factorial $(3 \times 2 \times 2)$. En el segundo experimento se evaluó el efecto de cuatro niveles de $\operatorname{BAP}(0,0.50,1 \mathrm{y}$ $2 \mathrm{mg} \mathrm{L}^{-1}$ ) y los medios de cultivos MS y WPM sobre la brotación de los explantes de $N$. alpina, los factores se ordenaron factorialmente $(4 \times 2)$. Ambos experimentos se dispusieron en un diseño completamente aleatorizado, se contó con un testigo absoluto y se establecieron diez repeticiones. Para la comparación entre medias se utilizó la Prueba de Rangos Múltiples de Tukey $(p<0.05)$. Los valores porcentuales fueron transformados, previo al análisis de varianza, mediante la transformación angular de Bliss (Bliss, 1934).

\section{Resultados y discusión}

\section{Ensayo de inducción de raíces}

Número de raíces. Para la variable número de raíces, existieron diferencias estadísticas entre las dosis hormonales. Se obtuvo 0.93 raíces por explante cuando se utilizó altas concentraciones hormonales $\left(2 \mathrm{mg} \mathrm{L}^{-1}\right.$ de AIB), seguido por el medio enriquecido con 0.50 $\mathrm{mg} \mathrm{L}^{-1} \mathrm{AIB}$ (0.45 raíces). Al comparar entre medios, el número de raíces fue superior en el medio WPM $(0.62)$ aunque no hubo diferencias estadísticas al compararlo con el medio MS (0.57) (Cuadro 1). Comparando los tratamientos evaluados con el testigo, en promedio, se obtuvo más raíces por explante en el testigo (0.59) que en los medios con fitohormonas (0.45) (Cuadro 2).

Estos valores son inferiores a los reportados por Martínez y Arena (1996) para la misma especie, quienes obtuvieron de 2 a 4 raíces; diferencia que se puede atribuir al material vegetal utilizado por estos investigadores, que consistió en plántulas de tres a cuatro semanas de edad, mientras que en este ensayo se probó la capacidad de enraizamiento de material que había sido subcultivado por varios años. Según Pierik (1990) el material vegetal influye en el desarrollo in vitro, variando especialmente según el genotipo, estado fisiológico y la edad de la planta.

Uribe et al. (2012) establecieron que el medio MS complementado con $3 \mathrm{mg} \mathrm{L}^{-1}$ de AIB es una buena combinación para el enraizamiento de Nothofagus glauca (Phil.) Krasser, quienes obtuvieron con esta concentración 5.10 raíces explante ${ }^{-1}$. Cabe indicar que los mencionados autores usaron como material inicial microtallos obtenidos del cultivo de embriones.

Raíz principal. La longitud en la raíz mayor presentó diferencias, tanto entre las dosis hormonales como entre los medios evaluados $(p<0.05)$. Los mejores valores se obtuvieron con los tratamientos: $0 \mathrm{mg} \mathrm{L}^{-1}$ BAP, $2 \mathrm{mg} \mathrm{L}^{-1}$ AIB $(0.42 \mathrm{~cm})$, y $0.50 \mathrm{mg} \mathrm{L}^{-1}$ AIB $(0.33 \mathrm{~cm})$. También hubo diferencia estadística entre los medios evaluados; en promedio, el mejor medio fue el WPM (0.44) frente al MS (0.22) (Cuadro 1). Comparando los tratamientos evaluados con el testigo, la raíz principal fue más larga cuando se utilizó fitohormonas (0.40), en relación al tratamiento testigo (0.33) (Cuadro 2).

Martínez y Arena (1996) concluyeron para la especie relacionada, Nothofagus pumillio (P. et E.) Krasser, se obtienen raíces más largas utilizando el medio Broadleave Tree Medium (BTM) adicionado con $0.60 \mathrm{mg} \mathrm{L}^{-1} \mathrm{AIB}$, logrando raíces de longitud media de $0.50 \mathrm{~cm}$, valor inferior al mejor promedio obtenido en el presente estudio. Cabe indicar que los mencionados investigadores sólo probaron el medio 
Cuadro 1. Promedios y cuadrados medios de las variables raíces por explante, longitud de la raíz mayor, porcentaje de enraizamiento y de callosidad sobre explantes de $N$. alpina bajo el efecto de los factores AIB, BAP y medios de cultivos

\begin{tabular}{|c|c|c|c|c|c|}
\hline \multirow[b]{2}{*}{ Fuentes de Variación } & \multirow[b]{2}{*}{ GL } & \multicolumn{4}{|c|}{ Atributos del explante } \\
\hline & & Raíces explante $\mathrm{e}^{-1}$ & $\begin{array}{l}\text { Longitud de la raíz mayor } \\
\qquad(\mathrm{cm})\end{array}$ & $\begin{array}{r}\text { Enraizamiento } \\
(\%)\end{array}$ & Callosidad \\
\hline \multicolumn{6}{|l|}{ Promedios $^{\dagger}$} \\
\hline \multicolumn{6}{|l|}{ AIB } \\
\hline $0.5 \mathrm{mg} \mathrm{L}^{-1}$ & & $0.45 \mathrm{~b}$ & $0.33 \mathrm{~b}$ & $15.75 \mathrm{c}$ & $35.00 \mathrm{~b}$ \\
\hline $1.0 \mathrm{mg} \mathrm{L}^{-1}$ & & $0.40 \mathrm{~b}$ & $0.23 \mathrm{c}$ & $21.00 \mathrm{~b}$ & $42.50 \mathrm{a}$ \\
\hline $2.0 \mathrm{mg} \mathrm{L}^{-1}$ & & $0.93 \mathrm{a}$ & $0.42 \mathrm{a}$ & $37.50 \mathrm{a}$ & $27.50 \mathrm{c}$ \\
\hline \multicolumn{6}{|l|}{ BAP } \\
\hline $0.0 \mathrm{mg} \mathrm{L}^{-1}$ & & $1.18 \mathrm{a}$ & $0.66 \mathrm{a}$ & $49.50 \mathrm{a}$ & $6.67 \mathrm{~b}$ \\
\hline $0.5 \mathrm{mg} \mathrm{L}^{-1}$ & & $0.00 \mathrm{~b}$ & $0.00 \mathrm{~b}$ & $0.00 \mathrm{~b}$ & $63.33 \mathrm{a}$ \\
\hline \multicolumn{6}{|l|}{ Medios de cultivo (MC) } \\
\hline MS & & $0.57 \mathrm{a}$ & $0.22 \mathrm{~b}$ & $20.00 \mathrm{~b}$ & $28.33 \mathrm{~b}$ \\
\hline WPM & & $0.62 \mathrm{a}$ & $0.44 \mathrm{a}$ & $29.50 \mathrm{a}$ & $41.67 \mathrm{a}$ \\
\hline \multicolumn{6}{|l|}{ Cuadrados medios } \\
\hline AIB & 2 & $3.36^{* * *}$ & $0.37^{* * *}$ & $5152.50^{* * *}$ & $2250.00^{* * *}$ \\
\hline BAP & 1 & $42.01^{* * *}$ & $12.94^{* * *}$ & $73507.50^{* * *}$ & $96333.30^{* * *}$ \\
\hline $\mathrm{MC}$ & 1 & 0.08 & $1.54^{* * *}$ & $2707.50^{* * *}$ & $5333.30^{* * *}$ \\
\hline AIB*BAP & 2 & $3.36^{* * *}$ & $0.37^{* * *}$ & $5152.50^{* * *}$ & $583.30^{* * *}$ \\
\hline $\mathrm{AIB} * \mathrm{MC}$ & 2 & $5.73^{* * *}$ & $1.81^{* * *}$ & $3752.50^{* * *}$ & $1583.30^{* * *}$ \\
\hline $\mathrm{BAP} * \mathrm{MC}$ & 1 & 0.06 & $1.54^{* * *}$ & $2707.50^{* * *}$ & $12000.00^{* * *}$ \\
\hline $\mathrm{AIB} * \mathrm{BAP} * \mathrm{MC}$ & 2 & $5.73^{* * *}$ & $1.81^{* * *}$ & $3752.50^{* * *}$ & $250.00^{* * *}$ \\
\hline Testigo vs Tratados & 1 & $35.85^{* * *}$ & $5.26^{* * *}$ & 33046.40 & $12129.80^{* * *}$ \\
\hline Total & 129 & & & & \\
\hline
\end{tabular}

$\dagger$ Medias seguidas por la misma letra no presentan diferencias estadísticas (Tukey, $\mathrm{p}<0.05$ )

$* * * \mathrm{p}<0.001$

BTM suplementado con diferentes concentraciones de AIB, la mitad de macronutrientes y 10 días de oscuridad; además de que utilizaron material vegetal juvenil.

Porcentaje de enraizamiento. Los mejores porcentajes de enraizamiento se presentaron en los tratamientos con las mayores dosis hormonales de AIB (1 y $2 \mathrm{mg} \mathrm{L}^{-1}$ ), presentándose un buen enraizamiento cuando el medio carecía de BAP $(49.50 \%)$. Este efecto hormonal se presentó tanto en el medio MS como en el WPM (Cuadro 1, Figura 1). Al comparar los medios, el porcentaje de brotes enraizados resultó significativamente superior cuando se usó el medio WPM (29.50\%) frente al MS (20.0\%). En promedio, el porcentaje de enraizamiento de los explantes, cultivados en los medios con fitohormonas $(24.80 \%)$, fue igual estadísticamente al testigo (25\%) (Cuadro 2).

Martínez y Arena (1997) lograron en N. pumillio hasta un $100 \%$ de brotes enraizados, utilizando el medio BTM con la mitad de macronutrientes suplementado con $2.46 \mathrm{mg} \mathrm{L}^{-1}$ de AIB. Uribe et al. (2012) en $N$. glauca obtuvieron hasta un $87.50 \%$ de enraizamiento adventicio utilizando el medio MS suplementado con $1 \mathrm{mg} \mathrm{L}^{-1}$ de AIB, valor parecido al encontrado en este trabajo al utilizar el mismo medio adicionado con 2 $\mathrm{mg} \mathrm{L}^{-1}$ de AIB mientras que cuando se utilizó $1 \mathrm{mg} \mathrm{L}^{-1}$ de AIB solamente se obtuvo el $40 \%$ de enraizamiento. El porcentaje mayor de brotes enraizados obtenidos en estos estudios puede deberse a las diferencias en el medio de cultivo, o podría ser una reacción a la mayor cantidad de hormona utilizada, o también 


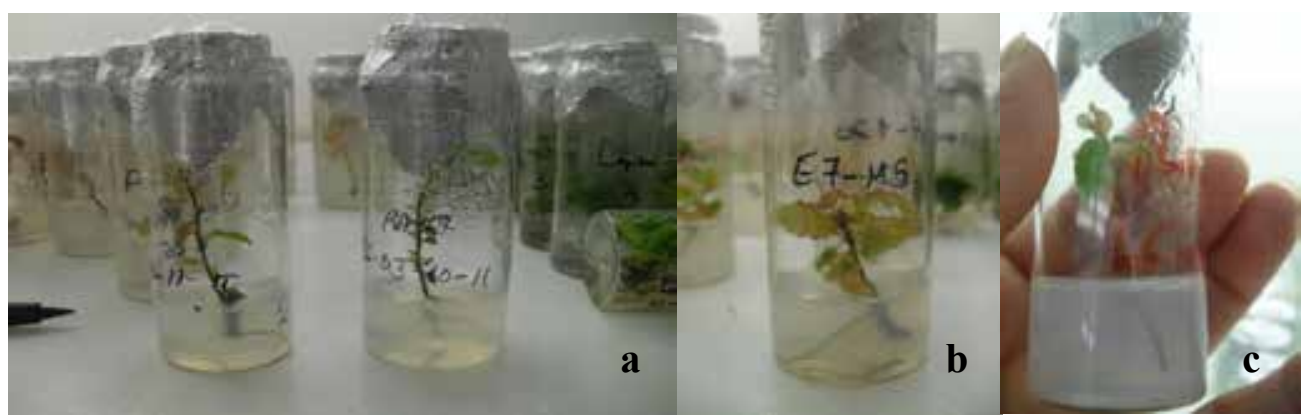

Figura 1. Inducción de raíces en diferentes medios: WPM $0.50 \mathrm{mg} \mathrm{L}^{-1} \mathrm{AIB}$ (a), MS $2 \mathrm{mg}$ $\mathrm{L}^{-1} \mathrm{AIB}$ (b), MS $1 \mathrm{mg} \mathrm{L}^{-1} \mathrm{AIB}+0.50 \mathrm{mg} \mathrm{L}^{-1}$ BAP (c)

Cuadro 2. Promedios de las variables raíces por explante, longitud de la raíz mayor, porcentaje de enraizamiento y de callosidad en explantes de $N$. alpina sin fitohormonas (testigo) y con fitohormonas (tratados)

\begin{tabular}{lcrrr}
\hline & \multicolumn{4}{c}{ Atributos del explante } \\
\cline { 2 - 5 } $\begin{array}{l}\text { Fuentes de } \\
\text { Variación }\end{array}$ & Raíces explante $^{-1}$ & $\begin{array}{c}\text { Longitud de la raíz mayor } \\
(\mathbf{c m})\end{array}$ & $\begin{array}{c}\text { Enraizamiento } \\
\text { (\%) }\end{array}$ & Callosidad \\
\hline Testigo & $0.45 \mathrm{~b}$ & $0.40 \mathrm{a}$ & $25.00 \mathrm{a}$ & $15.00 \mathrm{~b}$ \\
Tratados & $0.59 \mathrm{a}$ & $0.33 \mathrm{~b}$ & $24.80 \mathrm{a}$ & $35.00 \mathrm{a}$ \\
\hline
\end{tabular}

esta diferencia podría atribuirse al diferente material vegetal utilizado, pues Uribe et al. (2012) utilizaron microtallos obtenidos del cultivo de embriones.

Callosidad. La presencia de callos fue mayor en los tratamientos que incluyeron citoquinina y en el medio WPM. El uso de $1 \mathrm{mg} \mathrm{L}^{-1}$ de AIB aumenta la callosidad (Cuadro 1). En el medio WPM resultó un $41.66 \%$ de las muestras con callos, mientras que en el medio MS un $28.33 \%$ de las muestras presentaron callos. Martínez y Arena (1997) encontraron que el porcentaje de callosidad aumentaba en el medio BTM al aumentar la dosis de AIB (0.61-2.46) en un ensayo de enraizamiento de $N$. pumillio. Dichos autores no probaron concentraciones de BAP ni combinaciones AIB y BAP.

El promedio de producción de callos en los tratamientos, fue significativamente superior $(35 \%)$ comparado con el testigo (15\%) (Cuadro 2). Aunque este ensayo no tenía la finalidad de producción de callos, este resultado podría considerarse en futuros planes de propagación in vitro vía organogénesis. La producción de callos bajo las condiciones del ensayo fue comprobada por Murashige y Skoog (1962), quienes han señalado que diferentes combinaciones de auxinas y citoquininas producen callos, brotes o raíces, según la proporción en que se utilicen.
Interacciones en el ensayo de inducción de raíces. $\mathrm{Al}$ evaluar el número de raíces por explantes $(\mathrm{R} / \mathrm{E}) \mathrm{de}$ $N$. alpina en el medio de cultivo MS se observó que bajo una concentración de $0.50 \mathrm{mg} \mathrm{L}^{-1}$ de AIB, el nivel de BAP (0 y $\left.0.50 \mathrm{mg} \mathrm{L}^{-1}\right)$ no refleja ningún efecto en el número de R/E. Sin embargo, al haber adicionado $1 \mathrm{mg}$ $\mathrm{L}^{-1}$ de AIB, la adición de $\operatorname{BAP}\left(0.50 \mathrm{mg} \mathrm{L}^{-1}\right)$ disminuyó el número de $\mathrm{R} / \mathrm{E}$ de 1 a 0 raíces por explante. Este último efecto depresor del número de R/E del BAP fue similar al observado en concentraciones de AIB de 2 $\mathrm{mg} \mathrm{L}^{-1}$ pasando de 2.40 a 0 raíces por explante. En este medio de cultivo (MS), cuando el nivel de BAP es 0 $\mathrm{mg} \mathrm{L}^{-1}$, se observó que a medida que se incrementa la concentración de AIB el número de R/E se incrementó proporcionalmente.

Cuando el medio de cultivo fue WPM, se observó que bajo una concentración de $0.50 \mathrm{mg} \mathrm{L}^{-1}$ de AIB, el aumento de la concentración de BAP (0 y $0.50 \mathrm{mg}$ $\mathrm{L}^{-1}$ ) disminuyó el número de $\mathrm{R} / \mathrm{E}$ de 1.80 a 0 raíces por explante. Similar efecto del BAP sobre el número de $\mathrm{R} / \mathrm{E}$ se observó cuando la concentración de AIB fue de 1 y $2 \mathrm{mg} \mathrm{L}^{-1}$. En el medio de cultivo WPM, cuando el nivel de BAP es $0 \mathrm{mg} \mathrm{L}^{-1}$, se observó un alto (1.80), bajo (0.60) y medio (1.30) número de $\mathrm{R} / \mathrm{E}$ para las concentraciones de $0.50,1$ y $2{\mathrm{de} \mathrm{mg} \mathrm{L}^{-1}}^{-1}$ AIB, respectivamente (Figura 2a). Similares efectos se evidenciaron en el porcentaje de enraizamiento (Figura 2c) y en la longitud de la raíz mayor (Figura 

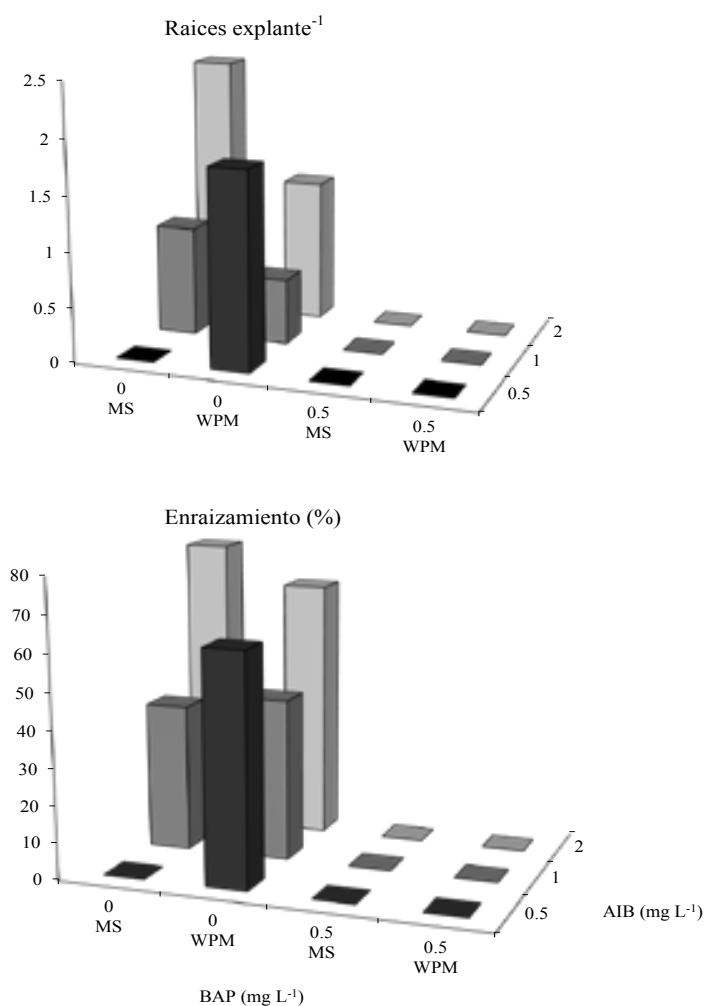
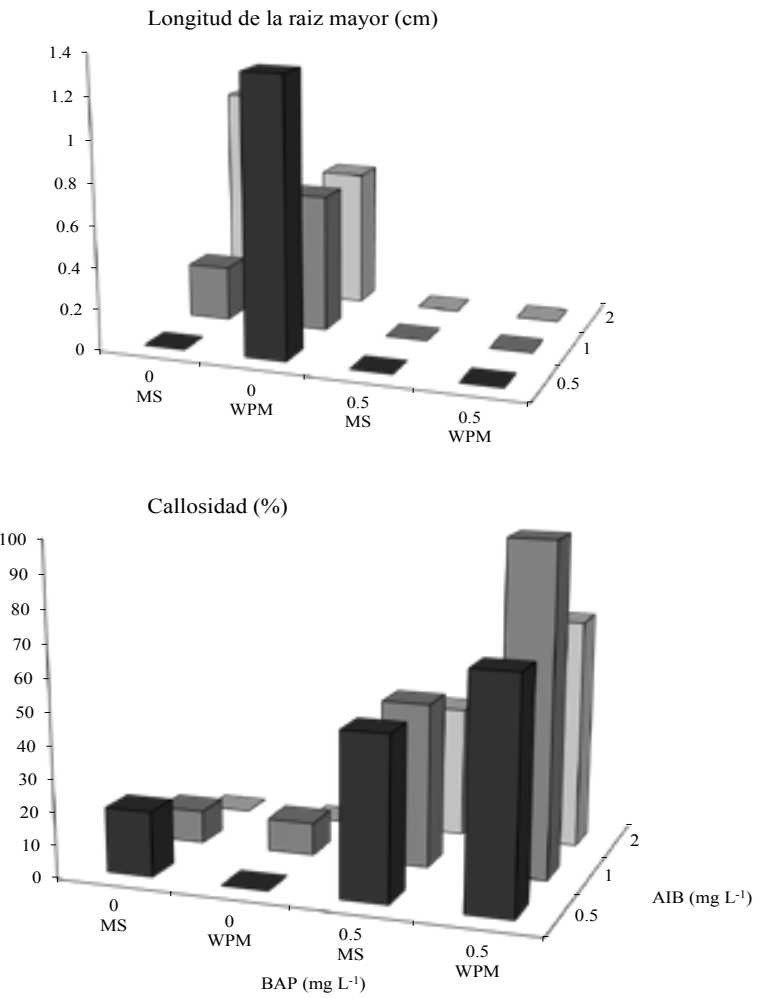

Figura 2. Efecto de la interacción AIB x BAP x MC (MS, WPM) sobre las variables raíces por explante (a), longitud de la raíz mayor (b), porcentaje de enraizamiento (c) y de callosidad (d) en explantes de $N$. alpina

2b), donde en el medio MS un mayor nivel de BAP produjo mejores resultados cuando el medio carecía de AIB; en cambio en el medio WPM el resultado fue mejor con el más bajo nivel de AIB probado. Tanto en el medio MS como en el WPM, la adición de BAP inhibió el desarrollo de raíces. No obstante, el porcentaje de callosidad fue superior en los medios que además de BAP fueron suplementados con $1 \mathrm{mg}$ $\mathrm{L}^{-1} \mathrm{AIB}$, siendo en el medio WPM donde se produjo más callosidad (Figura 2c).

\section{Ensayo de generación de brotes}

Número de brotes. Hubo diferencias $(\mathrm{p}<0.05)$ para la variable número de brotes, entre los tratamientos hormonales evaluados. El mayor número de brotes se generó sin adición de citoquinina. Entre medios también hubo diferencias estadísticas, resultando un mayor número de brotes en el medio MS (1.25) frente al medio WPM (1.05) (Cuadro 3). Al comparar los tratamientos con el testigo, no hubo diferencias estadísticas; en promedio se obtuvo 1.15 brotes tanto en el testigo como en los medios suplementados con hormonas (Cuadro 4). Esto concuerda con lo obtenido por Gómez et al. (2007), quienes al estudiar el efecto del subcultivo sucesivo sobre la caulogénegis adventicia en Eucaliptus globulus Labill, concluyeron que el repicar un material en un medio libre de hormonas ayuda a recuperar la competencia perdida o disminuida, permitiendo el aumento en la producción de microtallos.

Longitud de brotes. La longitud de los brotes $(\mathrm{cm})$ presentó diferencias, tanto entre los medios de cultivo como entre dosis hormonales; se obtuvo el valor promedio más alto en las plántulas cultivadas en el medio MS (0.60) y en ausencia BAP (0.81) (Cuadro 3 ). En promedio, los brotes crecieron más en altura (1.08 $\mathrm{cm}$ ) cuando los medios no fueron suplementados con hormonas (Cuadro 4). Sánchez et al. (2004) tuvieron buenos resultados en la inducción de yemas y tallos en Nothofagus procera (P. et E.) Oerts, al utilizar el medio MS con la concentración $0.50 \mathrm{mg} \mathrm{L}^{-1}$ de BAP y $0.05 \mathrm{mg} \mathrm{L}^{-1}$ de AIB. La diferencia en la concentración podría ser debido a que los mencionados autores utilizaron como material inicial embriones maduros. Por su lado, Martínez y Arena (1997) en la especie relacionada $N$. pumillio encontraron que el medio BTM (Broadleaved Tree Medium) con baja concentración salina y adicionada con glutamina fue adecuado para la multiplicación de los brotes siendo ésta afectada por las citocininas y el ácido giberélico. Martínez y Arena (1997) sólo probaron variantes del medio BTM. 
Cuadro 3. Promedios y cuadrados medios de las variables brotes por explante, longitud del brote, hojas por brote, porcentaje de brotación y de callosidad sobre brotes de $N$. alpina bajo el efecto de los factores BAP y medios de cultivos

\begin{tabular}{|c|c|c|c|c|c|c|}
\hline \multirow[b]{2}{*}{ Fuentes de Variación } & \multirow[b]{2}{*}{ GL } & \multicolumn{5}{|c|}{ Atributos del brote } \\
\hline & & Brotes explante $^{-1}$ & Longitud del brote $(\mathrm{cm})$ & Hojas brote $^{-1}$ & Brotación & Callosidad \\
\hline
\end{tabular}

Promedios $^{ \pm}$

BAP

\begin{tabular}{|c|c|c|c|c|c|c|}
\hline \multicolumn{2}{|l|}{$0.0 \mathrm{mg} \mathrm{L}^{-1}$} & $1.35 \mathrm{a}$ & $0.81 \mathrm{a}$ & $3.60 \mathrm{a}$ & $100.00 \mathrm{a}$ & $5.00 \mathrm{c}$ \\
\hline \multicolumn{2}{|l|}{$0.5 \mathrm{mg} \mathrm{L}^{-1}$} & $0.85 \mathrm{~b}$ & $0.34 \mathrm{c}$ & $1.60 \mathrm{~b}$ & $69.50 \mathrm{~d}$ & $65.50 \mathrm{a}$ \\
\hline \multicolumn{2}{|l|}{$1.0 \mathrm{mg} \mathrm{L}^{-1}$} & $1.15 \mathrm{ab}$ & $0.50 \mathrm{~b}$ & $1.70 \mathrm{~b}$ & $90.00 \mathrm{c}$ & $54.50 \mathrm{~b}$ \\
\hline \multicolumn{2}{|l|}{$2.0 \mathrm{mg} \mathrm{L}^{-1}$} & $1.25 \mathrm{a}$ & $0.21 \mathrm{~d}$ & $1.05 \mathrm{c}$ & $95.00 \mathrm{~b}$ & $50.00 \mathrm{~b}$ \\
\hline \multicolumn{7}{|c|}{ Medios de cultivo (MC) } \\
\hline \multicolumn{2}{|l|}{ MS } & $1.25 \mathrm{a}$ & $0.60 \mathrm{a}$ & $2.70 \mathrm{a}$ & $97.50 \mathrm{a}$ & $12.75 \mathrm{~b}$ \\
\hline \multicolumn{2}{|l|}{ WPM } & $1.05 \mathrm{~b}$ & $0.33 \mathrm{~b}$ & $1.28 \mathrm{~b}$ & $79.75 \mathrm{~b}$ & $74.750 \mathrm{a}$ \\
\hline \multicolumn{7}{|l|}{$\underline{\text { Cuadrados medios }}$} \\
\hline BAP & 3 & $0.93^{* *}$ & $1.35^{* * *}$ & $24.75^{* * *}$ & $3584.50^{* * *}$ & $14195.00^{* * *}$ \\
\hline $\mathrm{MC}$ & 1 & $0.80^{*}$ & $1.40^{* * *}$ & $40.61^{* * *}$ & $6301.20^{* * *}$ & $76880.00^{* * *}$ \\
\hline $\mathrm{BAP} * \mathrm{MC}$ & 3 & 0.33 & $0.58^{* * *}$ & $18.81^{* * *}$ & $1534.50^{* * *}$ & $7076.60^{* * *}$ \\
\hline Testigo vs Tratados & 1 & 1.38 & $0.33^{* * *}$ & $0.70^{* * *}$ & $1293.30^{* * *}$ & $17013.80^{* * *}$ \\
\hline Total & 89 & & & & & \\
\hline
\end{tabular}

†romedios con letras diferentes difieren estadísticamente de acuerdo al test de Tukey $(\mathrm{p}<0.05)$.

$* \mathrm{p}<0.05, * * \mathrm{p}<0.01, * * * \mathrm{p}<0.001$.

Número de hojas obtenidas. Similarmente, hay diferencias $(\mathrm{p}<0.05)$ en el número de hojas obtenidas, tanto entre medios como entre dosis hormonales. El mayor número de hojas se obtuvo en el medio MS (2.70) y en ausencia de citoquininas (3.60). Al comparar el promedio de los tratamientos con el testigo, se presentaron diferencias estadísticas; obteniéndose un promedio 4.35 hojas en los medios sin suplementación hormonal, mientras que en los medios suplementados el promedio fue de 1.99 hojas (Cuadro 4).

Sánchez et al. (2004) también consiguieron resultados similares en un ensayo de propagación in vitro de $N$. procera a partir de embriones aislados, pues el testigo fue superior a los tratamientos hormonales. A partir de este resultado, ellos concluyen que la elongación caulinar se ve restringida a medida que aumenta la concentración hormonal en el medio de cultivo, considerándose este comportamiento como un indicador de elevados niveles endógenos de reguladores del crecimiento vegetal (Sánchez et al., 2002), los que actúan como cofactores morfogénicos (Rey et al., 1994). El efecto inhibitorio de la elongación caulinar por el aumento en la concentración exógena de hormonas es diferente para las distintas hormonas (Tamas, 1995), por lo que la variación en los niveles, de auxina o citoquinina, tiene efectos distintos.

Brotación. El porcentaje de brotación presentó diferencias, tanto entre tratamientos hormonales como entre los medios probados; el resultado fue similar al que se obtuvo para la variable número de hojas: superior en el medio MS (97.50\%) y en ausencia de citoquininas $(100.00 \%)$. Se determinó diferencias significativas al comparar los medios tratados con el testigo, siendo el porcentaje de brotación superior en éste último (94.50\%) (Cuadro 4).

De acuerdo a estos resultados, la aplicación de citoquininas parece no ser indispensable para 
Cuadro 4. Promedios de las variables: brotes por explante, longitud del brote, hojas por brote, porcentaje de brotación y de callosidad en brotes de $N$. alpina sin fitohormonas (testigo) y con fitohormonas (tratados)

\begin{tabular}{|c|c|c|c|c|c|}
\hline \multirow[b]{2}{*}{ Fuentes de Variación } & \multicolumn{5}{|c|}{ Atributos del brote } \\
\hline & Brotes explante $^{-1}$ & $\begin{array}{l}\text { Longitud del brote } \\
\qquad(\mathrm{cm})\end{array}$ & Hojas brote $^{-1}$ & Brotación & Callosidad \\
\hline Testigo & $1.15 \mathrm{a}$ & $1.08 \mathrm{a}$ & $4.35 \mathrm{a}$ & $94.50 \mathrm{a}$ & $0.00 \mathrm{~b}$ \\
\hline Tratados & $1.15 \mathrm{a}$ & $0.46 \mathrm{~b}$ & $1.99 \mathrm{~b}$ & $88.60 \mathrm{~b}$ & $43.80 \mathrm{a}$ \\
\hline
\end{tabular}

la brotación, puesto que tanto en los medios con fitohormonas como en el testigo hubo una buena brotación. Esto se debe a que el material utilizado para este experimento ya contiene adecuados niveles endógenos de citoquinina; de acuerdo a Pierik (1990) este fenómeno se denomina habituación, por el que después de un número de subcultivos, las células pueden seguir creciendo sin adición de hormonas. Según Ahuja (1993), el desencadenamiento de la caulogénesis in vitro depende de una relación óptima entre las concentraciones totales de citoquininas y de auxinas exógenas y endógenas; aunque, la respuesta varía mucho dependiendo de la especie y del tipo de explanto utilizado.

Callosidad. También hubo diferencias estadísticas en los porcentajes de callosidad, tanto entre tratamientos hormonales como entre medios; siendo el tratamiento sin citoquinina el que resultó en un menor porcentaje $(5.00 \%)$ y el medio WPM (12.75\%) (Cuadro 3, Figura $3)$. No se generó callos en los explantes cultivados en los medios testigo, mientras que en los tratamientos hormonales se obtuvo un $43.80 \%$ en promedio
(Cuadro 4). El objetivo de este ensayo no era producir callos, no obstante este resultado indica la necesidad de utilizar hormonas cuando se desee producir callos.

Interacciones en el ensayo de multiplicación de brotes. Al evaluar la longitud del brote en explantes de $N$. alpina en una condición de $0 \mathrm{mg} \mathrm{L}^{-1}$ de BAP, se observó una mayor longitud del brote en el medio de cultivo WPM $(0.90 \mathrm{~cm})$ con respecto a la longitud observada en el medio MS $(0.70 \mathrm{~cm})$. Sin embargo, al enriquecer el medio de cultivo con BAP la longitud del brote fue menor en el medio WPM. Con una concentración de $0.50 \mathrm{mg} \mathrm{L}^{-1}$ de BAP la longitud del brote pasó de 0.50 a $0.20 \mathrm{~cm}$, con una concentración de $1 \mathrm{mg} \mathrm{L}^{-1}$ la longitud del brote pasó de 0.80 a 0.20 $\mathrm{cm}$ y, una concentración de $2 \mathrm{mg} \mathrm{L}^{-1}$ la longitud del brote pasó de 0.40 a $0.10 \mathrm{~cm}$ (Figura 4a). El efecto de los tratamientos en el número de hojas por brote fue similar al observado en la longitud de brotes (Figura 4b). El porcentaje de callosidad registrado, independientemente de los tratamientos hormonales, su superior en el medio WPM (Figura 4d).

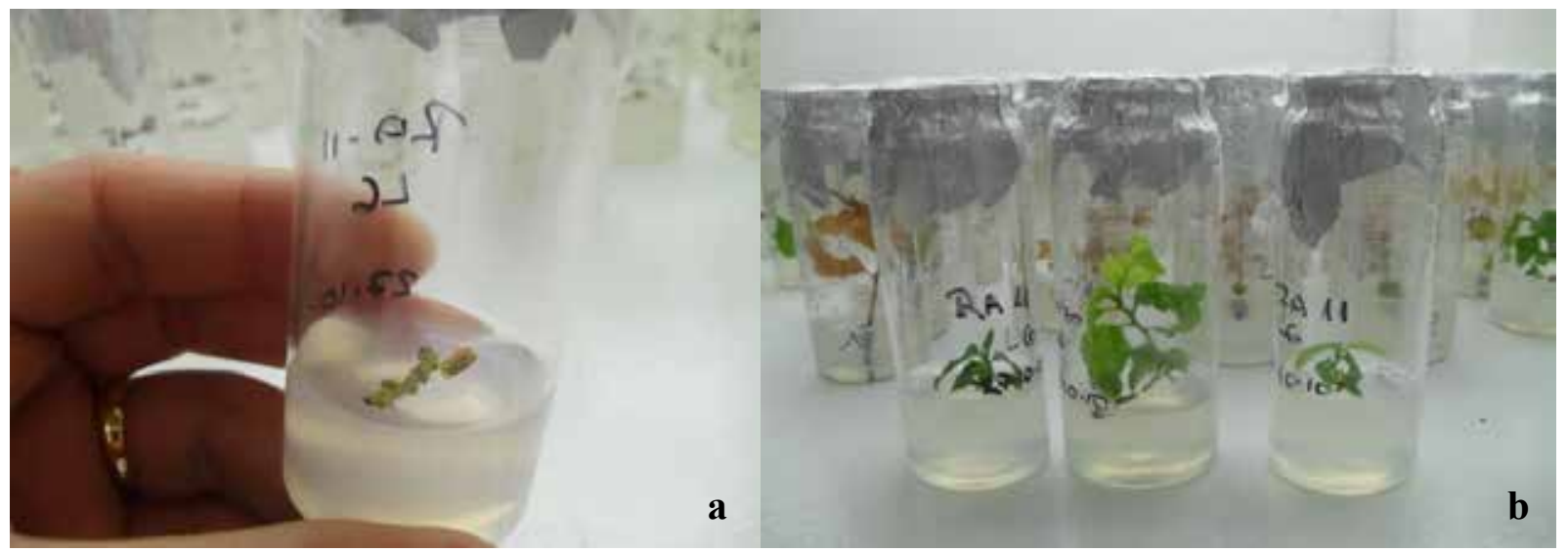

Figura 3. Presencia de callos en los tratamientos. WPM $0.20 \mathrm{mg} \mathrm{L}^{-1} \mathrm{AIB}+1 \mathrm{mg} \mathrm{L}^{-1} \mathrm{BAP}$ (a), WPM-T4 0.20 mg L $\mathbf{L}^{-1} \mathrm{AIB}+2 \mathrm{mg} \mathrm{L}^{-1}$ BAP (b) 

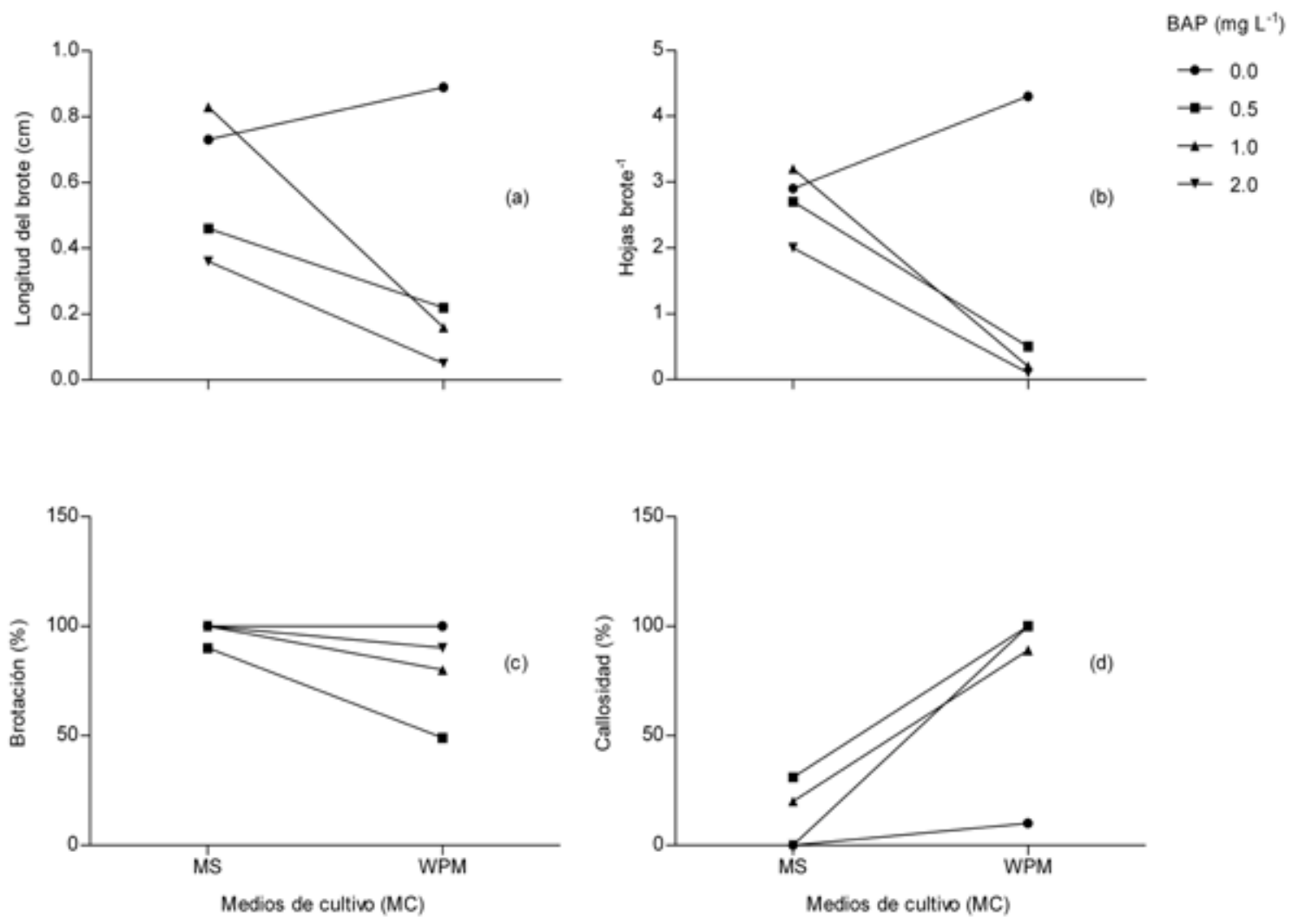

Figura 4. Efecto de la interacción BAP x MC sobre las variables longitud del brote (a), hojas por brote (b), porcentaje de brotación (c) y de callosidad (d) en brotes de $N$. alpina

\section{Conclusiones}

$E^{1}$ 1 tipo de medio de cultivo influye en el enraizamiento de brotes de N. alpina, encontrándose diferencias entre los medios utilizados (Murashigge y Skoog (MS) y Wood Plant Medium (WPM)). Por lo general, se puede decir que los tratamientos que incluyeron citoquinina originaron callos y no enraizaron; siendo mayor la presencia de callos en el medio WPM. Los mejores resultados en número de raíces y longitud de raíz principal se registraron en el medio suplementado con $2 \mathrm{mg} \mathrm{L}^{-1} \mathrm{AIB}$; en el medio MS para el primer caso y WPM para la segunda variable. El mayor porcentaje de enraizamiento se presentó en el medio MS y la mejor concentración hormonal fue $2 \mathrm{mg}$ $\mathrm{L}^{-1} \mathrm{AIB}$, que coinciden en ser los tratamientos que presentaron menos callosidad, considerándose la mejor opción para enraizamiento de vitroplantas de $N$. alpina. En las variables: raíces por explante y callosidad, se obtuvo mejores resultados cuando los medios fueron suplementados con hormonas; al contrario, la longitud de la raíz mayor fue superior cuando los medios no habían sido suplementados con hormonas. Con los resultados de este ensayo se recomienda probar concentraciones hormonales de AIB que vayan de 2 a $4 \mathrm{mg} \mathrm{L}^{-1}$, sin adición de citoquininas, para intentar superar el porcentaje de enraizamiento obtenido en este trabajo, y para la inducción de la brotación, se recomienda el cultivo in vitro en medio MS donde se presentó una menor formación de callos. Los resultados en cuanto a la brotación, número de raíces y porcentaje de enraizamiento son más bajos que lo reportado por otros autores que trabajaron con material vegetal juvenil; sin embargo fueron notablemente superiores a la propagación en el medio de cultivo con que se había realizado, hasta ese momento, subcultivos sucesivos del material utilizado. 


\section{Bibliografía}

Ahuja, M. 1993. Biotechnology and Clonal Forestry. In: Ahuja M. and Libby, W. (Editors) Clonal Forestry I. Genetic and Biotechnology. SpringerVerlag. Berlín. 135-144 p.

Bliss, C.I. 1934. The method of probits. Science, 79: 38-39.

García, L. 2014. Biología reproducitiva de Nothafagus alpina. Tesis previa a la obtención del título de Doctora de Ciencias Forestales. Universidad Austral de Chile. 103 pp.

Gómez, C., Ríos, D., Sánchez-Olate, M. 2007. Efecto del subcultivo sucesivo sobre la caulogénegis adventicia en Eucaliptus globulus Labill. Bosque 28(1): 13-17.

Ikemori, Y.K., Penchel, R.M., and Bertolucci, F.L.G. 1994. Integrating biotechnology into Eucalyptus breeding. International Wood Biotechnology Symposium. August 31th- September 1th. Tokio, Japan. pp: 77-84.

Lloyd, G., Mccown, B. 1981. Commercially feasible micropropagation of montain laurel, Kalmia latifolia, by use of shoot tip culture. Com. Proc. Int. Plant Prop. Soc., 30: 421-327.

Martínez, P.G. and Arena, M. 1996. In vitro Propagation of Nothofagus nervosa (Phil) Dim. et Mil. Phyton 58(1/2): 1-7.

Martinez, P.G. and Arena, M. 1997. Micropropagación de Nothofagus pumilio (Poepp. et Endl.) Krasser. Bosque 18(2): 43-50.

Muhitch, M., Fletcher, J. 1985. Influence of culture age and Spd treatment on the accumulation of phenolic compounds in suspension cultures. Plant Physiology 78(1): 25-28.

Murashige, T. and Skoog, F. 1962. A revised medium for rapid growth and bio-assays with tobacco tissue cultures. Physiol Plant 15(3): 473-497.
Pierik, R. 1990. Cultivo in vitro de las plantas superiors. Ediciones Mundi Prensa. Madrid. p 325.

Rey, M., Tiburcio, A., Díaz-Sala, C., Rodríguez, R. 1994. Endogenous polyamine concentration in juvenile, adult and in vitro reinvigorated hazel. Tree Physiology 14(2): 191-200.

Sabja, A., Ortiz, O., Triviño, C. 2008. Avances de clonación in vitro de árboles adultos de raulí (Nothofagus alpina Poepp. et Endl.) Oerst.) para propagación comercial. Agrociencia 42(5): 595603.

Sánchez-Olate, M., Ríos, D., Pedraza, M., Pereira, G., Castellanos, H. y Escobar, R. 2004. Propagación in vitro de Nothofagus procera ((Poepp. et Endl.) Oerst.) a partir de embriones aislados. Bosque (Valdivia) 25(1): 123-128.

Sánchez-Olate, M., Ríos, D., Revilla, M., Rodríguez, R. 2002. Participación de poliaminas endógenas en el desarrollo de injertos y brotes epicórmicos de nogal. Agrociencia 17(2): 215-219.

Schlatter, J. y Steuer, H. 2005. Selección de sitios para el establecimiento de ensayos clonales de raulí (Nothofagus alpina). En: Rodríguez y Molina M. (2005). Clonación del raulí. Estado actual y perspectivas. CEFOR, INFOR. p 174.

Sedjo, R.A. 1997. The forest sector: Important innovations. Discussion Paper 97-42. Resource for the Future, Washington, D.C. p 55.

Tamas, I. 1995. Hormonal regulation of apical dominance. In: Davies P. J. (ed.), Plant hormones. Physiology, Biochemistry and Molecular Biology. Kluwer Academic Publisher. Netherlands. p. 572597.

Uribe, M., Ulloa, J., Delaveau, C., Sáez, K., Muñoz, F. y Cartes, P. 2012. Influencia de las auxinas sobre el enraizamiento in vitro de microtallos de Nothofagus glauca (Phil.) Krasser. Gayana Bot. 69(1): 105-112. 